\title{
The Relationship Between Coat Color and Reproductive Performance of Dairy Cows in Algeria
}

\author{
Sara Lamari* and Youcef Saber \\ Department of Agronomy, Faculty of Nature and Life Sciences, University of Ferhat Abbas (Sétif)19000, Algeria \\ *Corresponding author's Email: lamarisara@gmail.com; (1) ORCiD: 0000-0001-8651-1968
}

\begin{abstract}
The objective of the current study was to analyze the reproduction parameters of 48 dairy cows (29 Montbeliardes and 19 Normandes) and their relationship to coat color. Cows were imported from European countries and raised in the semi-arid region of Sétif in Algeria. The findings showed that the cows of the Montbéliarde breed were more fertile and of greater reproduction efficiency, compared to Normandes. Regarding the Montbéliarde breed, the intervals between calving and calving to conception were respectively 378.34 and 98.65 days, which were shorter than those of the Normandes breed (67 and 22 days, respectively). Normandes cows registered a higher number of services per conception $(1.54 \pm 0.9)$, compared to Montbeliarde cows $(1.34 \pm 0.55)$. Calving to the first service interval of the Normandes (76 days) was longer by 5 days than that of the Montbéliarde breed. The coats of Montbéliarde cows $(51 \%)$ were whiter than those of Normandes $(48 \%)$. A darker hair coat probably assured protectivity against thermal stress and greater efficiency of reproduction. The interval between calving in Montbéliarde cows was significantly affected by coat color; the interval between calving of cows with a colored coat was shorter (358 days) than whiter cows (400 days). For Normandes, cows with a colorful coat required fewer services per conception number (1.44). Hair works as a temperature regulator and may affect reproduction performances. The results of the current study suggest the possibility of integrating coat color into animal selection. It can be assumed that colored coats for Montbéliarde and Normande breeds appear to be related to their reproductive efficiency (interval between calving and number of services per conception, respectively).
\end{abstract}

Keywords: Coat color, Dairy cows, Reproduction, Semi-arid

\section{INTRODUCTION}

In Algeria, dairy cattle breeding has been selected as a major axis for the supply of dairy products. Milk consumption has been increasing with population growth (Makhlouf and Montaigne, 2016). To meet the growing demand for dairy products, Algeria has opted for the development of a cattle breeding policy based on the import of heifers with a high genetic potential of dairy products from Europe (Mefti Korteby et al., 2016). Among the pure breeds imported, there are the Montbéliarde and Normande.

In European developed countries, all dairy cows (Fleckvieh, Montbéliarde, Holstein), produce on average 60 liters/day of milk, however, it is five times less with only an average of 12 liters per day in Algeria (Mefti Korteby et al., 2016). The potential of milk production of cows differs among the breeds and even among individual cows within the same breed raised under various environmental conditions (Aggarwal and Upadhyay, 2012).

The hair is an aspect of environmental adaptation, which reflects the response of the animals to their environments. So, coats of cattle are adapted to withstand the harsh hot climate weather. In addition, animal coat changes in response to seasonal environmental changes (Brinkmann et al., 2012). Coat color is a trait that is often hypothesized to contribute to heat tolerance in animals (Leite et al., 2018).

On top of that, the genotype-environment interactions lead to differences in the expression of reproduction performance. There is a relationship between coat color and reproductive performance in dairy cattle, particularly when animals are reared under conditions of high temperatures and intense solar radiation (Becerril et al., 1994). The 305-d milk yield of cows with black hair coats is moderately reduced without affecting milk composition (Anzures-Olvera et al., 2019).

The light coming from the invisible part of solar radiation (infrared spectrum) is completely absorbed regardless of the coat color, while the visible part of the radiation is absorbed according to the coat color of animals. Heat stress can reduce the fertility of dairy cows (Ryan et al., 1992; Ealy et al., 1993). In order to minimize the effects of thermal stress on reproduction performance, animals with a coat more suited to the conditions present in North Africa can be selected 
(Lamari et al., 2013). Therefore, the present study investigated the relationship between the coat color and the reproduction performance of Montbéliarde and Normande cows.

\section{MATERIALS AND METHODS}

\section{Ethical approval}

The study was carried out with existing reproduction information files of dairy cows and by taking pictures of each animal. The experiment did not involve animal handling.

\section{Animals}

Information on this study was obtained in collaboration with the executives of the school farm in the semi-arid area of Sétif, Algeria from February to May 2018. The study included a total of 48 imported dairy cows of two different breeds (29 Montbéliarde and 19 Normande cows), subjected to the same breeding system and the same environmental conditions. To be included in the current study, cows had to be free from any presented with reproductive diseases or abortions. Any cows not meeting these inclusion criteria were excluded (10 Normande and 1 Montbeliarde) from enrollment in this study. Sample size determination was based upon our primary outcome of interest, reproductive performance.

All the cows selected were either gestating or drying up. Animals were fed twice a day a ration based on forages mostly collected from the home pasture land and purchased concentrate. Detection of estrus was made by visual observation 4 times a day for 20 minutes. The PRID protocol was preferred by the veterinarian to synchronize the estrus and artificial insemination was adopted by the manager.

All this information was collected in individual files, including data relating to the cow (identification number, breed, date of birth, etc.) and events relating to reproduction (dates of calving, dates of inseminations, number of services by conception, etc.). Four fertility parameters were estimated; the number of services per conception (SPC), calving to first service interval (FSI), calving to conception interval (CI), the interval between calving (ICC).

\section{Determination of the percentage of the coat color}

The percentage of the white color related to the entire body surface area was measured visually (Becerril and Wilcox, 1992). It was estimated by taking pictures of both sides of each animal. However, the tail, head, legs, and belly regions were not included in the measurement.

\section{Statistical analysis}

The mean and standard deviation are calculated and tests of normality (Kolmogorov-Smirnov) and homogeneity of variances (Levene's test) were performed for all parameters. Normalizing logarithmic transformations are used when the distribution of the variables studied is abnormal. A non-hierarchical classification (VL) method that uses the distribution of central trend statistics is performed to identify the different classes of hair coat traits. Subjects were divided into two classes of Coat dark (class 1) and Coat White (class 2) with $1<42 \%$ and $2>42 \%$ of white color, respectively. To determine the percentage effect of coat white color on reproductive parameters, one-way ANOVA was used for each breed separately because the breed effect was observed on reproduction. The type of analysis of variance was chosen based on the nature of the variables. The Kruskal-Wallis test was used in cases where the normality of the data was not assured. The significance level was set at $\mathrm{p}<0.05$ when conducting Levene's test. All the analyses were carried out by the SPSS package program, version 21 software.

\section{RESULTS}

\section{Average reproduction performance and white coat color}

Generally, the coat color varies from total white to colored with a total average of $49.79 \pm 27.56 \%$ of white color but the white color was more dominant in Montbéliarde cows $(51 \pm 28 \%)$ than in Normande cows $(47.89 \pm 27.55 \%)$. In fact, school farm cows were inseminated $72.62 \pm 28.25$ days after calving and conception was produced after $1.44 \pm 0.74$ attempts with high SPC $(1.54 \pm 0.90)$ in Normande cows, when compared to the SPC of Montbéliarde cows (1.34 \pm 0.55). The cows of both breeds carried out the first service almost at the same time, calving to first service interval for the Normande cows was longer than the Montbéliarde cows' interval by 5 days.

Total School farm cows (Montbeliarde and Normande) required 107.25 \pm 53.18 days to achieve conception after calving. The interval between successive calving was $404.93 \pm 129.55$ days in the school farm, but Montbéliarde cows were characterized by a shorter CI and ICC, compared to those of Normande cows (Table 1). 
Table 1. Mean and standard deviation values of percentage of white coat color and reproductive performances of Montbeliarde and Normande cows involved in the semi-arid area of Algeria

\begin{tabular}{lccc}
\hline Traits & $\begin{array}{c}\text { Montbeliarde (29) } \\
\mathbf{M} \pm \text { SD }\end{array}$ & $\begin{array}{c}\text { Normande (19) } \\
\mathbf{M} \pm \text { SD }\end{array}$ & $\begin{array}{c}\text { Total (48) } \\
\text { M } \pm \text { SD }\end{array}$ \\
\hline C $(\%)$ & $51 \pm 28$ & $47.89 \pm 27.55$ & $49.79 \pm 27.56$ \\
SPC & $1.34 \pm 0.55$ & $1.54 \pm 0.90$ & $1.44 \pm 0.74$ \\
FSI (days) & $70.55 \pm 28.26$ & $75.78 \pm 28.71$ & $72.62 \pm 28.25$ \\
CI (days) & $98.65 \pm 53.43$ & $120.36 \pm 51.42$ & $107.25 \pm 53.18$ \\
ICC (days) & $378.34 \pm 49$ & $445.52 \pm 192.87$ & $404.93 \pm 129.55$
\end{tabular}

C\%: Percentage of white coat color, SPC: Number of services (inseminations) per conception, FSI: Calving to first service interval, CI: Calving to conception interval, ICC: Interval between calving, M: Mean, SD: Standard deviation

\section{Relationship between the proportion of white coat color and reproduction parameters}

The results in Table 2 indicated the significant effect $(\mathrm{p}<0.05)$ of coat color on reproductive parameters for the two breeds. Indeed, the fertility of cows of two breeds was influenced by the proportion of the white of the coat, the ICC and the SPC for the Montbéliarde and Normande cows respectively were linked to the white color of the coat $(p<0.05)$

\section{The Montbéliarde breed}

The results of the analysis of variance indicated that the ICC of the Montbéliarde cows was significantly affected by the coat color $(\mathrm{p}<0.05$, Table 2$)$. Cows with colored coats $(<42 \%)$ achieved shorter successive calving intervals, compared to Montbéliade cows with white coat color $(>42 \%)$. It is also noted that colored cows are characterized by better reproductive performance (SPC, FSI, and CI).

\section{The Normande breed}

According to the results of Table 2, the SPC in the Normande breed is dependent on the color of the coat. The more colorful the cows $(<42 \%)$, the lower the number of SPC and consequently, the lower the CI, compared to other cows. In contrast, FSI and ICC are relatively long; ICC is longer in cows with a high percentage of white color (over $42 \%)$.

Table 2. Effect of coat color on reproduction parameters of Montbéliarde and Normande cows in the semi-arid area of Algeria

\begin{tabular}{|c|c|c|c|c|}
\hline C \% & $\begin{array}{c}\text { SPC } \\
M \pm \mathrm{SD}\end{array}$ & $\begin{array}{c}\text { FSI } \\
\mathrm{M} \pm \mathrm{SD}\end{array}$ & $\begin{array}{c}\mathrm{CI} \\
\mathrm{M} \pm \mathrm{SD}\end{array}$ & $\begin{array}{c}\mathrm{ICC} \\
\mathrm{M} \pm \mathrm{SD}\end{array}$ \\
\hline \multicolumn{5}{|c|}{ Montbeliarde (29) } \\
\hline Class 1 (15) & $1.20 \pm 0.56$ & $67.40 \pm 26.79$ & $80.66 \pm 39.82$ & $358.20 \pm 44.66^{\mathrm{a}}$ \\
\hline Class 2 (14) & $1.50 \pm 0.51$ & $73.92 \pm 30.39$ & $117.92 \pm 60.56$ & $399.92 \pm 45.43^{\mathrm{b}}$ \\
\hline $\mathrm{p}$ & $0.09^{\mathrm{ns}}$ & $0.53^{\mathrm{ns}}$ & $0.06^{\mathrm{ns}}$ & $0.02 *$ \\
\hline \multicolumn{5}{|c|}{ Normande (19) } \\
\hline Class 1 (9) & $1.44 \pm 0.52^{\mathrm{a}}$ & $85.88 \pm 30.36$ & $114 ., 00 \pm 44.84$ & $493.55 \pm 260.56$ \\
\hline Class 2 (10) & $2.30 \pm 0.94^{\mathrm{b}}$ & $66.70 \pm 25.20$ & $126.10 \pm 58.51$ & $402.30 \pm 98.32$ \\
\hline $\mathrm{p}$ & $0.04 *$ & $0.14^{\mathrm{ns}}$ & $0.70^{\mathrm{ns}}$ & $0.30^{\mathrm{ns}}$ \\
\hline
\end{tabular}

\section{DISCUSSIONS}

The results of the current study showed that there was a relationship between coat color and reproductive parameters. These results were similar to those obtained by Lamari et al. (2015) where they reported that Montbéliarde cows with a high percentage of white color of the coat achieved a shorter FSI.

The results of the current study showed that coat color had a significant effect on the ICC of the Montbéliarde breed. The colored Montbéliarde cows were characterized by better reproductive performance (more fertile), compared to white cows (with the percentage of white coat color $>42 \%$ ) and they performed shorter successive calving intervals (358.20 days). The number of services per conception, FSI, and CI were not influenced by the percentage of white coat color but these intervals were relatively reduced in colored cows. The results of the present study disagree with the results obtained by Lamari et al. (2015), who reported that cows with a high percentage of white-colored coats had a shorter interval between calving and first insemination. Moreover, the coat color had an effect on the SPC for the Normandes 
breed, cows with a better SPC (1.44) were characterized by a reduced percentage of white coat color. These results were in agreement with those obtained by Maia et al. (2003), who reported that colored cows gained shorter SPC.

Furthermore, Lamari et al. (2013) found that the white color had no effect on the SPC. The FSI reflects both the resumption of cyclicity and the quality of the detection of heat. The results showed that the white Normande cows resumed their cyclicity at $66.70 \pm 25.20$ days after calving, while FSI of colored cows takes place at $85.88 \pm 30.36$ days after calving. Similarly, Lamari et al. (2015) observed that the white cows resumed their cyclicity sooner than the colored cows but in Montbeliarde cows, there was a negative correlation coefficient $(r=-0.359)$ between calving to first service interval (FSI) and percentage of white coat color $(\mathrm{C} \%)$. Cows with whiter coats showed less change in reproductive performance.

The CI was relatively short in colored cows, compared to white cows, confirming the observations for Lamari et al. (2018). However, the ICC of white cows was shorter than that of colored cows. Nejad et al. (2016) reported that under heat stress conditions, coat color may play a role in stress severity by absorbing heat and solar radiation based on white and black colors. According to Magona et al. (2009) and Riley et al. (2012), animals with a dark coat color absorbed more heat compared to animals with light coat color. Lamari et al. (2015) indicated that cows with white coats were characterized by low absorption of thermal radiation which increased their capacity to dissipate heat. However, Bertipaglia et al. (2005) found that the white coat presents an effective barrier against thermal stress. And according to (Maia et al., 2003), the white coat offered better protection against direct solar radiation.

\section{CONCLUSION}

The study investigated the relationship between hair coat color and reproduction performances of Montbéliarde and Normande breeds in the semi-arid area of Algeria. Results showed that coat color affected reproduction parameters, including ICC for Montbeliarde breed and SPC for Normande breed. Colored hair coat cows had more efficient reproduction with relatively reduced ICC for Montbeliarde cows and a reduced SPC of Normand cows. The results suggested that hair coat color can be used as a factor to select resilient and more adaptable animals to hot climates, and it can also improve the knowledge of farmers to have the best reproductive performance under heat stress conditions.

\section{DECLARATIONS}

\section{Authors' contribution}

Sara Lamari carried out the statistical analysis, supervised and followed the practical part, Youcef Saber carried out the practical part of the experiment. The two authors participated in the interpretation of the results and the drafting of the manuscript. The authors declare that they have verified and confirmed all the data and the final version of the article.

\section{Competing interests}

The authors have not declared any conflict of interest.

\section{Acknowledgments}

The authors acknowledge the efforts of all farm staff who saved their precious time and collaborated in data collection without which this work would not have been possible.

\section{Ethical consideration}

Ethical issues (including plagiarism, consent to publish, misconduct, data fabrication and/or falsification, double publication and/or submission, and redundancy) have been checked by all the authors.

\section{REFERENCES}

Aggarwal A, and Upadhyay R (2012). Heat stress and animal productivity. Springer, India, p. 188. Available at: https://link.springer.com/book/10.1007/978-81-322-0879-2

Anzures-Olvera F, Véliz FG, de Santiago A, García JE, Mellado J, Macías-Cruz U, Avendaño-Reyes L, and Mellado M (2019). The impact of hair coat color on physiological variables, reproductive performance and milk yield of Holstein cows in a hot environment. Journal of Thermal Biology, 81: 82-88. DOI: https://www.doi.org/10.1016/j.jtherbio.2019.02.020

Becerril CM, and Wilcox CJ (1992). Determination of percentage of white coat color from registry certificates in Holstein. Journal of Dairy Science, 75: 3582-3586. DOI: https://www.doi.org/10.3168/jds.S0022-0302(92)78135-1

Becerril CM, Wilcox CJ, and Wiggans GR (1994). Transformation of measurements percentage of white coat color for Holsteins and estimation of heritability. Journal of Dairy Science, 77(9): 2651-2657. Available at: https://pubag.nal.usda.gov/download/41478/PDF 
Bertipaglia ECA, Silva RG, and Maia ASC (2005). Fertility and hair characteristics of Holstein cows in the tropics. Animal Reproduction, 2(3): 187-194. Available at: http://www.cbra.org.br/pages/publicacoes/animalreproduction/issues/download/AR044.pdf

Brinkmann L, Gerken M, and Riek A (2012). Adaptation strategies to seasonal changes in environmental conditions of a domesticated horse breed, the Shetland pony (Equus ferus caballus). The Journal of Experimental Biology, 215: 1061-1068. DOI: https://www.doi.org/10.1242/jeb.064832

Ealy D, Drost M, and Hansen PJ (1993). Developmental changes in embryonic resistance to adverse effects of maternal heat stress in cows. Journal of Dairy Science, 76: 2899-2905. DOI: https://www.doi.org/10.3168/jds.s0022-0302(93)77629-8

Nejad JG, Kim BW, Lee BH, and Sung KI (2016). Coat and hair color: Hair cortisol and serotonin levels in lactating Holstein cows under heat stress conditions. Animal Science Journal, 88: 190-194. DOI: https://www.doi.org/10.1111/asj.12662

Lamari S, Madani T, and Allouche L (2013). Relationship between fertility and the characteristics of the coat of Montbéliard cows in Algeria. Rencontres Recherches $\quad$ Ruminants, 20 Available at: http://www.journees3r.fr/IMG/pdf/Texte 6 repro S Lamari.pdf

Lamari S, Madani T, Allouche L, and Bouamama L (2015). Relationship between coat color and reproductive performance of Montbéliard cows in Algeria. Rencontres Recherches. Ruminants, 22: 214. Available at: http://www.journees3r.fr/IMG/pdf/Texte_7_affiche_Reproduction_S-Lamari.pdf

Lamari S, Madani T, and Allouche L (2018). Hair characteristics and cortisol hair analysis as indicators of fertility in dairy cows. Livestock Research for Rural Development, 30(3): Article \#49. Available at: http://www.lrrd.org/lrrd30/3/lamar30049.html

Leite JHGM, Silva RG, da Silva WST, da Silva WE, Paiva RDM, Sousa JER, LAB Asensio, and Façanha DAE (2018). Locally adapted Brazilian ewes with different coat colors maintain homeothermy during the year in an equatorial semiarid environment. International Journal Biometeorol, 62(9): 1635-1644. DOI: https://www.doi.org/10.1007/s00484-018-1563-x

Magona JW, Walubengo J, Olaho-Mukani W, Jonsson NN, and Eisler MC (2009). Diagnostic value of rectal temperature of African cattle of variable coat colour infected with trypanosomes and tick-borne infections. Vetérinaire Parasitologie, 160: 301-305. DOI: https://www.doi.org/10.1016/j.vetpar.2008.11.020

Maia ASC, Silva RG, and Bertipaglia ECA (2003). Características do pelame de vacas Holandesas em um ambiente tropical: Um estudo genético e adaptativo. Revu Brasileira de Zootecnia, 32: 843-853. Available at: https://www.scielo.br/scielo.php?pid=S1516-35982003000400009\&script=sci_abstract\&tlng=en

Makhlouf M, and Montaigne E (2016). The world dairy market dynamic. Livestock Research for Rural Development, 28(10): Article \#187. Available at: http://www.lrrd.org/lrrd28/10/makh28187.html

Mefti Korteby H, Bredj A, Maouche S, and Deradji B (2016). Comparison of the reproduction performance of Fleckvieh and Montbéliarde cows under Algerian breeding conditions. Agriculture Journal, 7: 15-22. Available at: https://revue-agro.univsetif.dz/documents-agri/numero11-2016/MEFTI.pdf

Riley DG, Chase CC Jr, Coleman SW, and Olson TA (2012). Genetic assessment of rectal temperature and coat score in Brahman, Angus and Romosinuano crossbred and straightbred cows under subtropical summer conditions. Livestock Science, 148: 109118. DOI: https://www.doi.org/10.1016/j.livsci.2012.05.017

Ryan PD, Boland MP, Kopel E, Armstrong D, Munyakazi L, Godke RA, and Ingraham RH (1992). Evaluating two different evaporative cooling management systems for dairy cows in a hot, dry climate. Journal of Dairy Science, 75: 1052-1059. Available at: https://www.journalofdairyscience.org/article/S0022-0302(92)77849-7/pdf 